Discussion Paper No. 755

\title{
VERTICAL SEPARATION AS A DEFENSE AGAINST STRONG SUPPLIERS
}

\author{
Noriaki Matsushima \\ Tomomichi Mizuno
}

September 2009

The Institute of Social and Economic Research

Osaka University

6-1 Mihogaoka, Ibaraki, Osaka 567-0047, Japan 


\title{
Vertical separation as a defense against strong suppliers*
}

\author{
Noriaki Matsushima ${ }^{\dagger}$ \\ Institute of Social and Economic Research, Osaka University \\ Tomomichi Mizuno \\ Competition Policy Research Center, Japan Fair Trade Commission
}

September 10, 2009

\begin{abstract}
We provide a simple model to investigate decisions about vertical separation. The key feature of this model is that more than one input is required for the final product of the downstream monopolist. We show that as the bargaining powers of independent complementary input suppliers grow larger, the downstream monopolist tends to separate from its input units. The results are related to a visible difference between the vertical structures of Japanese and US auto assemblers.
\end{abstract}

JEL Classification Codes: L13, L22, M11.

Key Words: Multiple inputs; Bargaining; Disintegration; Double marginalization

\footnotetext{
${ }^{*}$ We would like to thank Toshihiro Matsumura, Joji Tokui, and seminar participants at Shinshu University for their helpful comments. Especially, we would like to thank Didier Laussel for his careful and constructive suggestions. The first author gratefully acknowledges financial support from a Grant-in-Aid for Encouragement of Young Scientists from the Japanese Ministry of Education, Science and Culture. Needless to say, we are responsible for any remaining errors. The views expressed herein are those of the authors and should not be interpreted as those of the Japan Fair Trade Commission.

${ }^{\dagger}$ Corresponding author: Noriaki Matsushima, Institute of Social and Economic Research, Osaka University, Mihogaoka 6-1, Ibaraki, Osaka 567-0047, Japan. Phone: +81-6-6879-8571. E-mail: nmatsush@iser.osaka-u.ac.jp
} 


\section{Introduction}

Vertical separation has become a widespread phenomenon in the industrialized world. Examples of industries where vertical separation is a key feature of the organization of production abound: aircraft, cars, computers, audio/video systems, and so on. For example, in the automobile industry, suppliers have a significant role in US, European, and Japanese auto manufacturing and therefore in the quality of the final product (Richardson (1993)). Japanese assemblers, especially, often spin off parts development and manufacturing to independently managed yet closely linked suppliers (Ahmadjian and Lincoln (2001)). Moreover, automobiles are developed and manufactured by OEMs and their supplier networks, who produce as much as 70 percent of the value of a vehicle. Consequently, the cost and quality of a vehicle are functions of the productivity of a network of firms working in collaboration (Dyer and Nobeoka (2000)).

The degree of vertical separation (integration) varies between firms although vertical separation has become a widespread phenomenon. The automobile industry is a typical example. Japanese auto assemblers are known to be substantially less vertically integrated than their US counterparts (see, for instance, Cusumano and Takeishi (1991) and the references therein). Large Japanese auto assemblers such as Toyota and Nissan rely on suppliers for both design and manufacture of components traditionally produced in-house by GM and Ford. As summarized in Dyer (1996), there are several explanations that a high (resp. low) degree of vertical integration emerged in the US (resp. Japan). One explanation is preference for vertical interactions among firms. The US auto companies tend to eliminate some negative effects from interactions with their trading partners. For instance, Perry (1989) and Scherer (1980) point out managements' desire to grow and reduce dependency on outside suppliers. Moreover, Emerson (1962) and Pfeffer and Salancik (1978) mention that firms lose power when they increase their dependency on outside suppliers. On the other hand, Japanese cultural norms and values result in a high level of "goodwill trust" in 
Japan, which translates into cooperative interfirm relationships (Dore (1983), Sako (1991), Hill (1995)). Another explanation of the differences between the US and Japanese in the degree of vertical integration is based on the lack of an open market for corporate control in Japan (Sheard (1994)) and the limitations of Japanese financial markets (Nishiguchi (1994)).

Although those explanations summarized by Dyer (1996) sound plausible, we provide a new strategic reason for the difference between the US and Japan. We think that a simple key feature to explain those differences is that more than one input is required for the final products of those manufacturers. In automobile product development, the degree of vertical separation (integration) for a single manufacturer is the consequence of hundreds of individual procurement choices, ranging from simple supply contracts for commodity components to complex arrangements for cutting-edge technology development (Novak and Stern (2009)).

We provide a simple model to investigate decisions of vertical separation and show several results that have not been explained in previous research (we mention the difference between this model and those in related previous studies later). The key feature of this model is that more than one input is required for the final product of the downstream monopolist. ${ }^{1}$ This feature is consistent with the examples mentioned above. The model can be also applied to other industries. For instance, in the aircraft industry two major firms, Airbus and Boeing, rely heavily on firm-specific inputs (e.g., engines, wings, horizontal stabilizers) produced by independent manufacturers, and then sell their aircraft to airline

\footnotetext{
${ }^{1}$ This setting is related to models with complementary suppliers (Economides and Salop (1992), Nalebuff (2000), Baldwin and Woodard (2007), Casadesus-Masanell et al. (2007), and Maruyama and Minamikawa (2009)). Those papers discuss how mergers among complementary suppliers appear and/or how those mergers change equilibrium outcomes. Such complementary suppliers provide their products directly to consumers. This setting is quite different from ours. Note that the meaning of the term 'vertical integration' in these papers is different from that in our paper. Although a merger among complementary suppliers is called 'vertical integration' in these papers, in our model the term indicates a merger between an upstream and a downstream firm.
} 
companies, which are final customers (Beelaerts van Blokland et al. (2008)).

The model structure is as follows. There is a downstream monopolist $D$ that uses two inputs; $A$ and $B$. The inputs are produced by an independent upstream supplier $A$ and a production unit inside the downstream firm $D$ respectively. The wholesale price of input $A$ is determined by bargaining between the downstream firm and the supplier. Under this condition, we consider two cases: (1) the downstream firm produces units of input $B,(2)$ the downstream firm separates from its input production unit. The separated unit (supplier $B$ ) supplies to the downstream firm $D$ to maximize its own profit. ${ }^{2}$ We show that as the bargaining power of the independent supplier $A$ increases, the downstream monopolist tends to separate from its input unit. A corollary of the result is that when the bargaining power of the independent supplier $A$ is large enough, vertical separation is always profitable for the downstream monopolist.

Our paper shows that when the number of high-quality input suppliers that tend to have stronger bargaining power is large, assemblers tend to withdraw from design and/or manufacture of other complementary components, as the Japanese assemblers did. Following the discussion in Clark and Fujimoto (1991) and Clark (1989), we now explain that Japanese suppliers indeed have strong bargaining power and/or provide high-quality product to auto assemblers. Clark and Fujimoto (1991) and Clark (1989) examine the impact of "project scope" in the global auto industry. The impact is a measure of the uniqueness of the part played and the extent of development carried out by outside suppliers in project performance. The authors found that $67 \%$ of Japanese projects were "black box," or developed by suppliers, compared with $16 \%$ of US vehicles. They argue that the black-box system is effective because the link between design and manufacturing is strong. They argue that the high percentage of unique parts and high supplier involvement contributes to an observed

\footnotetext{
${ }^{2}$ We assume that the downstream firm cannot merge with supplier $A$. A more detailed discussion of the assumption is provided in Section 2.
} 
Japanese advantage in project lead time and cost. ${ }^{3}$ This fact is consistent with our result: As the number of high-quality independent input suppliers, which tend to have stronger bargaining power, increases the downstream monopolist tends to separate from its input production units.

Several researchers have investigated how the structure of vertical organizations is determined in competitive environments (Bonanno and Vickers (1988), Gal-Or (1999), Choi and Yi (2000), Chen (2001, 2005), Lin (2006), Arya et al. (2008), Matsushima (forthcoming)). Although these papers consider downstream competition to derive results for vertical separation, we show that vertical separation is profitable even with only one downstream firm. An exception is Laussel (2008) who explicitly incorporates complementary inputs in an attempt to examine why vertical integration does not occur. Besides several differences in the setup (which we will mention later), the present paper differs from Laussel (2008) as our focus is primarily on the relation between the degree of vertical separation and procurement conditions.

In a broad sense, since the seminal work by Coase (1937), the problem of vertical integration/separation has long been discussed by many researchers in the transactioncost-based approach. The related papers mainly deal with well-known hold-up problems that illustrate the underinvestment hypothesis (e.g., Grout (1984) and Tirole (1986)). Coase (1937) suggested that transaction costs might be avoided or reduced via other organizational structures, and Klein et al. (1978) and Williamson (1979) suggested vertical integration as an organizational response. The focus of this approach has been on comparing costs internal to a transaction, between organizing the transaction within a firm or through the market. ${ }^{4}$ Complementary to the transaction-cost based approach, this paper emphasizes

\footnotetext{
${ }^{3}$ Many researchers also point out that Japanese suppliers have superior technology, which contributes to better performance by Japanese automakers (see Hemmert (1999) and the references therein).

${ }^{4}$ Using the property rights approach to address the question of whether vertical integration can escape the hold-up problem, Grossman and Hart (1986) and Hart and Moore (1990) considered how a particular
} 
the importance of incorporating multiple inputs into the standard models with vertical relations.

The model setup is somewhat similar to those in the literature on patent pools although the motivations of these papers are quite different from ours (Lerner and Tirole (2004), Kim (2004), and Schmidt (2008)). These papers discuss how vertical integration and/or patent pools (alliances among patent holders) alter the prices of patented inputs. However, the incentives for vertical integration between upstream and downstream firms are not discussed.

The remainder of this paper is organized as follows. Section 2 formulates the model. Section 3 presents the results. Section 4 extends the basic model. Section 5 briefly discusses the relation between our results and the differences between US and Japanese automakers. Section 6 concludes the paper.

\section{The model}

Consider a downstream monopolist $D$ that uses two inputs, $A$ and $B$. The inputs are produced by an independent upstream supplier $A$ and a production unit inside the downstream firm $D$, respectively. The wholesale price of input $A$ is determined by bargaining between the downstream firm and the supplier.

The demand for the product is linear:

$$
p=1-Q
$$

where $p$ is the market price and $Q$ is the output supplied by the downstream firm. A unit

ownership structure affects the parties' exposure to hold-ups. Che and Sákovics (2008) provided an excellent brief survey of the hold-up problem. The topic of vertical foreclosure is also related to the problem of vertical integration. The vertical foreclosure issue primarily concerns the relation between vertical integration and the competitiveness of downstream firms (e.g., Ordover et al. (1990) and Hart and Tirole (1990)). See also O'Brien and Shaffer (1992), McAfee and Schwartz (1994), Gaudet and Long (1996), Ma (1997), Riordan (1998), and Choi and Yi (2000). Rey and Tirole (2007) provide an excellent survey of the literature. 
of final product is made with one unit of input $A$ and one unit of input $B$ :

$$
Q=\min \left\{q_{A}, q_{B}\right\}
$$

where $q_{i}$ is the amount of input $i(i=A, B)$. That is, the downstream firm uses Leontief production technology. The firms incur no marginal cost for units of product.

In this paper, we consider two cases: (1) the downstream firm produces units of input $B$, (2) the downstream firm separates from its input production unit. The separated unit (supplier $B$ ) supplies to the downstream firm $D$ to maximize its own profit (see Figure 1).

\section{[Figure 1 here]}

We now discuss two reasons for our assumption that the downstream firm cannot merge with firm $A$. First, when firm $A$ is an essential input supplier, vertical integration between firm $A$ and a downstream firm tends to be prohibited by antitrust authorities. In general, downstream firms compete, and they usually procure their inputs from common suppliers (Ahmadjian and Lincoln (2001)), although we use a model with a downstream monopolist to simplify the analysis. The common supplier in our model is firm $A$, which supplies essential inputs for the industry. In this situation, a vertical merger between firm $A$ and a downstream firm is generally prohibited by antitrust authorities because of the foreclosure problem (Rey and Tirole (2007)). Second, we can regard firm $A$ as a labor union in the downstream firm. In standard oligopoly models with labor unions, each downstream firm negotiates with its labor union, which maximizes the product of its wage level and number of employees (see, for instance, Horn and Wolinsky (1988a,1988b), Davidson (1988), Dowrick (1989), Mumford and Dowrick (1994), Naylor (2002), Lommerud et al. (2003), and Lommerud et al. (2009)). The setting employed here is the standard one concerning the objective function of labor union. ${ }^{5}$

\footnotetext{
${ }^{5}$ The second explanation seems unsuitable in the case of US and Japanese auto assemblers discussed in Section 5 because it is often recognized that US labor unions have stronger bargaining power than
} 
We assume that the input prices are determined through Nash bargaining. The solution is input prices $w_{A}$ and $w_{B}$ such that $w_{i}$ is the Nash solution to the bargaining problem between supplier $i$ and the downstream firm, given that both expect to agree upon the price $w_{j}$. That is, given $w_{j}$, the bargaining problem between supplier $i$ and the downstream firm is described by the payoff pairs $B_{i}^{I}=\left\{\left[w_{i} q_{i}, \pi_{D}\right] \mid w_{i} \geq 0\right\}$ and the disagreement point $(0,0)$, where $\pi_{D}$ is the profit of the downstream firm. The solution is given by:

$$
w_{i}=\arg \max _{w_{i}} \alpha_{i} \log \left[w_{i} q_{i}\right]+\left(1-\alpha_{i}\right) \log \pi_{D},
$$

where $\alpha_{i} \in[0,1]$ measures the bargaining power of supplier $i$ relative to that of the downstream firm. This is a departure from Laussel (2008) where each input supplier has the same bargaining power. Needless to say, the case of $\alpha_{A}=\alpha_{B}$ is a special case of our specification. Moreover, we thoroughly investigate how procurement conditions of the downstream firm affect the decision about vertical separation (see Sections 3 and 4).

The game runs as follows. First, the suppliers and the downstream firm negotiate the wholesale prices $w_{i}(i=A, B) .{ }^{6}$ Second, given the wholesale prices, the downstream firm sets its quantity supplied.

\section{Result}

We first consider two cases: (1) the downstream firm produces units of input $B$, and (2) the downstream firm separates from its input production unit. We then compare the two cases.

\footnotetext{
Japanese ones. However, as mentioned in Section 4, the existence of independent input suppliers including a labor union in itself triggers the emergence of other vertically separated input units. Therefore, the second explanation is plausible in the case of US and Japanese auto assemblers.

${ }^{6}$ We only consider the case in which each upstream firm uses a simple linear price contract. Even though those upstream firms use two-part tariff contracts, the essence of our main result does not change.
} 


\subsection{No vertical separation}

In this subsection, the downstream firm has the input production unit that makes input $B$. Given the wholesale price $w_{A}$, the maximization problem of the downstream firm is

$$
\max _{Q}\left(1-Q-w_{A}\right) Q
$$

The first-order condition leads to

$$
Q=q_{A}=\frac{1-w_{A}}{2}, \quad \pi_{D}=\frac{\left(1-w_{A}\right)^{2}}{4} .
$$

As mentioned earlier, the wholesale price $w_{A}$ is determined through Nash bargaining (see (2)). Applying the maximization problem in (2) to this situation, we have

$$
w_{A}^{N}=\frac{\alpha_{A}}{2}, \quad \pi_{A}^{N}=\frac{\alpha_{A}\left(2-\alpha_{A}\right)}{8}, \quad \pi_{D}^{N}=\frac{\left(2-\alpha_{A}\right)^{2}}{16},
$$

where the superscript ' $\mathrm{N}$ ' denotes the equilibrium outcome in which the downstream firm does not separate. As the bargaining power of supplier $A$ increases, the wholesale price $w_{A}$ and the profit of supplier $A$ increase.

\subsection{Vertical separation}

In this subsection, the downstream firm separates from its input production unit, and then receives inputs from suppliers $A$ and $B$. Given the wholesale prices $w_{A}$ and $w_{B}$, the maximization problem of the downstream firm is

$$
\max _{Q}\left(1-Q-w_{A}-w_{B}\right) Q
$$

The first-order condition leads to

$$
Q=q_{A}=q_{B}=\frac{1-w_{A}-w_{B}}{2}, \pi_{D}=\frac{\left(1-w_{A}-w_{B}\right)^{2}}{4}
$$

As mentioned earlier, the wholesale prices $w_{A}$ and $w_{B}$ are determined through Nash bargaining (see (2)). Applying the maximization problem in (2) to this situation, we have 
the first-order conditions of the Nash bargaining problems:

$$
2 w_{A}-\alpha_{A}+\alpha_{A} w_{B}=0, \quad 2 w_{B}-\alpha_{B}+\alpha_{B} w_{A}=0
$$

Solving the simultaneous equations, we have

$$
\begin{aligned}
& w_{A}^{S}=\frac{\left(2-\alpha_{B}\right) \alpha_{A}}{4-\alpha_{A} \alpha_{B}}, w_{B}^{S}=\frac{\left(2-\alpha_{A}\right) \alpha_{B}}{4-\alpha_{A} \alpha_{B}}, w_{A}^{S}+w_{B}^{S}=\frac{2\left(\alpha_{A}+\alpha_{B}-\alpha_{A} \alpha_{B}\right)}{4-\alpha_{A} \alpha_{B}} \\
& \pi_{A}^{S}=\frac{\alpha_{A}\left(2-\alpha_{A}\right)\left(2-\alpha_{B}\right)^{2}}{2\left(4-\alpha_{A} \alpha_{B}\right)^{2}}, \pi_{B}^{S}=\frac{\alpha_{B}\left(2-\alpha_{B}\right)\left(2-\alpha_{A}\right)^{2}}{2\left(4-\alpha_{A} \alpha_{B}\right)^{2}}, \pi_{D}^{S}=\frac{\left(2-\alpha_{A}\right)^{2}\left(2-\alpha_{B}\right)^{2}}{4\left(4-\alpha_{A} \alpha_{B}\right)^{2}}
\end{aligned}
$$

where the superscript ' $\mathrm{S}$ ' denotes the equilibrium outcome in which the downstream firm separates. As the bargaining power of supplier $A$ increases, $w_{A}$ increases but $w_{B}$ decreases. The converse also holds. As the bargaining power of supplier $B$ increases, $w_{B}$ increases but $w_{A}$ decreases. Because the competition structure between the suppliers is strategic substitute (see (4)), an increase in the wholesale price of supplier $i$ leads to a decrease in that of supplier $j(i=A, B, j \neq i)$.

\subsection{Comparison}

We now compare the results in the previous two subsections. First, we compare the total wholesale prices in the two cases. When the input unit is not separated (resp. separated), the wholesale price is $w_{A}^{N}\left(r e s p . w_{A}^{S}+w_{B}^{S}\right)$. The difference between them is

$$
w_{A}^{S}+w_{B}^{S}-w_{A}^{N}=\frac{\alpha_{B}\left(2-\alpha_{A}\right)^{2}}{2\left(4-\alpha_{A} \alpha_{B}\right)} \geq 0 .
$$

Except for the case in which $\alpha_{B}=0$, vertical separation increases per unit production cost of the downstream firm. This is related to the discussion in Cournot (1838). When independent upstream firms sell perfect complements, the total price of the complements is inefficiently higher because those upstream firms do not internalize the double marginalization problem. In fact, we can easily find that vertical separation decreases the profit of the downstream firm:

$$
\pi_{D}^{S}-\pi_{D}^{N}=-\frac{\alpha_{B}\left(2-\alpha_{A}\right)^{3}\left(8-\alpha_{B}\left(2+\alpha_{A}\right)\right)}{16\left(4-\alpha_{A} \alpha_{B}\right)^{2}} \leq 0 .
$$


We now show the incentive to separate from an input production unit. To investigate this incentive, we compare $\pi_{D}^{D}+\pi_{B}^{D}$ in (6) with $\pi_{D}^{N}$ in (3). The difference between them is

$$
\pi_{D}^{S}+\pi_{B}^{S}-\pi_{D}^{N}=\frac{\alpha_{B}\left(2-\alpha_{A}\right)^{2}\left(8 \alpha_{A}-\left(4+\alpha_{A}^{2}\right) \alpha_{B}\right)}{16\left(4-\alpha_{A} \alpha_{B}\right)^{2}} .
$$

From this equation, we have the following proposition.

Proposition 1 The integrated downstream firm has an incentive to separate its input production unit if and only if

$$
\alpha_{B}<\frac{8 \alpha_{A}}{4+\alpha_{A}^{2}}
$$

We easily derive the corollaries of Proposition 1.

Corollary 1 When supplier A has full bargaining power with respect to the downstream firm $\left(\alpha_{A}=1\right)$, vertical separation is always profitable for the integrated downstream firm.

Corollary 2 For any $\alpha_{A}(>0)$, there exists $\bar{\alpha}_{B}(>0)$ such that for any $\alpha_{B}<\bar{\alpha}_{B}$, vertical separation is profitable for the integrated downstream firm.

Roughly speaking, the equilibrium incentive of vertical separation might be reminiscent of the term "divide and rule" ("divide et impera") which is an economic strategy of gaining and maintaining power by breaking up larger concentrations of power into chunks that individually have less power than the one implementing the strategy.

To explain the intuition behind Proposition 1, we compare $w_{A}^{N}$ in (3) with $w_{A}^{S}$ in (5). The difference between them is

$$
w_{A}^{S}-w_{A}^{N}=-\frac{\alpha_{A} \alpha_{B}\left(2-\alpha_{A}\right)}{2\left(4-\alpha_{A} \alpha_{B}\right)} \leq 0
$$

Vertical separation induces supplier $A$ to lower its wholesale price $w_{A}$ when $\alpha_{A}>0$ and $\alpha_{B}>0$. This is because upstream firms do not fully exert monopoly power because of the double marginalization problem mentioned above (Cournot (1838) and Sonnenschein 
(1968)). This diminishes the profit of supplier $A$, and a portion of the monopoly profit of supplier $A$ is transferred to supplier $B$ through competition between the suppliers (see Figure 2). In particular, if the bargaining power of supplier $A$ is strong ( $\alpha_{A}$ is large), the decrease in the wholesale price $w_{A}$ is large (see (11)). ${ }^{7}$ Note that because vertical separation causes the standard double marginalization problem, it diminishes the quantity supplied by the downstream monopolist from $Q^{N}$ to $Q^{S}$ (see Figure 2).

[Figure 2 here]

Robustness Using a setting similar to that in this section, we now discuss the robustness of Proposition 1. This proposition states that when the bargaining power of supplier $B$ is weak, vertical separation tends to be profitable. We now slightly alter the basic setting to show a similar result to Proposition 1. We suppose that potential suppliers are able to supply input $B$ at a constant marginal cost $c$. Supplier $B$ has full bargaining power with respect to the downstream firm. When $c$ is sufficiently low, supplier $B$ sets its wholesale price at $c$ because of the Bertrand competition among them. The joint profit of the downstream and the separated upstream firm (supplier $B$ ) is

$$
\Pi \equiv\left[P\left(Q\left(w_{A}(c)+c\right)\right)-\left(w_{A}(c)+c\right)\right] Q\left(w_{A}(c)+c\right)+c Q\left(w_{A}(c)+c\right)
$$

where $P(\cdot)$ is the price of the final product, $Q(\cdot)$ is the quantity supplied by the downstream firm, and $w_{A}(c)$ is the wholesale price set by supplier $A$. Note that when $c=0$, this is equal to the profit when they are integrated. Differentiating the joint profit with respect

\footnotetext{
${ }^{7}$ We can easily show this using a partial derivative of $w_{A}^{S}-w_{A}^{N}$. Differentiating $w_{A}^{S}-w_{A}^{N}$ with respect to $\alpha_{A}$, we have

$$
\frac{\partial\left(w_{A}^{S}-w_{A}^{N}\right)}{\partial \alpha_{A}}=-\frac{\alpha_{B}\left(8\left(1-\alpha_{A}\right)+\alpha_{A}^{2} \alpha_{B}\right)}{2\left(4-\alpha_{A} \alpha_{B}\right)^{2}} \leq 0 .
$$
}


to $c$, we have

$$
\begin{aligned}
\frac{\partial \Pi}{\partial c} & =-\left(w_{A}^{\prime}(c)+1\right) Q\left(w_{A}(c)+c\right)+Q\left(w_{A}(c)+c\right)+c Q^{\prime}\left(w_{A}(c)+c\right)\left(w_{A}^{\prime}(c)+1\right) \\
& =-w_{A}^{\prime}(c) Q\left(w_{A}(c)+c\right)+c Q^{\prime}\left(w_{A}(c)+c\right)\left(w_{A}^{\prime}(c)+1\right) .
\end{aligned}
$$

When $c$ converges to zero, this converges to $-w_{A}^{\prime}(0) Q\left(w_{A}(0)\right)$. This is positive if and only if $w_{A}^{\prime}(c)<0$ for any $c$. The condition seems to be natural. Firm $A$ decreases its wholesale price as the other (competitive) supplier sets a higher price equal to $c .^{8}$

Proposition 2 Under a general (inverse) demand function $P(\cdot)$, when $c$ is sufficiently small and $w_{A}^{\prime}(c)<0$ for any $c$, vertical separation is profitable for the downstream and the separated upstream firm.

Potential suppliers It may be claimed that the result depends on the assumption that no potential competitors of the suppliers exist. Even if there are potential substitutes for the incumbent suppliers, our result holds true under some conditions. For instance, suppose that potential suppliers are able to supply inputs $A$ and $B$ at constant marginal costs $\bar{w}_{A}$ and $\bar{w}_{B}$ respectively. Those marginal costs are the upper bounds of the wholesale prices set by the incumbent suppliers. In this setting, $\alpha_{A}$ is large and $\bar{w}_{B}$ is sufficiently small, so vertical separation of supplier $B$ from the downstream firm tends to be profitable. ${ }^{9}$ The reason why this holds is simple. Because $\bar{w}_{B}$ is the upper bound of the wholesale price $w_{B}$ set by supplier $B$, a lower $\bar{w}_{B}$ is somewhat similar to the case in which supplier $B$ has lower bargaining power, which compels it to set a higher $w_{B}$.

Production technology In this section, we assume that the production technology of the downstream firm is Leontief. Some may claim that Leontief technology is crucial

\footnotetext{
${ }^{8} w_{A}^{\prime}(c)<0$ if $w Q^{\prime \prime}(w+c)+Q^{\prime}(w+c)<0$ (this is a sufficient condition). This condition, of course, includes the case in which the inverse demand function is linear.

${ }^{9}$ The calculus is highly complex, and is available from the authors on request.
} 
to derive our result. We can show that a similar result can be derived if the production technology of the downstream firm is Cobb-Douglas (see Technical Appendix). ${ }^{10}$

\section{Multiple suppliers}

We extend the basic setting in the previous section. Consider a downstream monopolist that requires $N$ inputs. $m$ inputs are produced by independent upstream suppliers $I_{i}$ $(i=1,2, \ldots, m)$ respectively $(m<N)$. The remaining inputs are produced by production units inside the downstream firm $\left(I_{i}(i=m+1, \ldots, N)\right)$. To simplify the analysis, we assume that the wholesale prices of input $I_{i}$ are unilaterally determined by the suppliers. ${ }^{11}$

The demand for the product is the same as in the previous section. The production function is expressed by

$$
Q=\min \left\{q_{i}, q_{2}, \ldots, q_{N}\right\}
$$

where $q_{i}$ is the amount of input $i(i=1,2, \ldots, N)$. That is, the production technology of the downstream firm is Leontief. The firms incur no marginal cost for units of product.

In this extended model, we consider the decision regarding the number of input production units that are separated from the downstream firm. We denote the number as $n$.

Given the wholesale prices $w_{i}(i=1,2, \ldots, m+n)$, the optimal quantity supplied by

\footnotetext{
10 Thesmar and Thoenig (2007) also consider the situation in which vertical separation appears. They show that an increase in the degree of vertical separation amplifies elasticity to demand shocks of firms' sales and employment. Moreover, by using French firm-level data sets from 1984 to 1999, they show that the theoretical results are consistent with their empirical results. In their model, the monopoly downstream firm uses two inputs and has Cobb-Douglas production technology. When one input division is separated, the separated supplier and the downstream firms enter into a nonlinear price contract. Moreover, the property of the input is different from that in our model. These differences lead to the different results in their paper.

${ }^{11}$ After we show the result in this section, we briefly mention the case in which each independent supplier has a different bargaining power.
} 
the downstream firm is

$$
Q=\frac{1-\sum_{i=1}^{m+n} w_{i}}{2}
$$

The maximization problem of supplier $i$ is

$$
\max _{w_{i}} \pi_{U i}=w_{i} \frac{1-\sum_{i=1}^{m+n} w_{i}}{2}
$$

The first-order conditions of the suppliers lead to

$$
w_{i}=\frac{1}{1+m+n}, \quad \pi_{D}=\frac{1}{4(1+n+m)^{2}}, \quad \pi_{U i}=\frac{1}{2(1+n+m)^{2}}
$$

The joint profit of the downstream and $n$ suppliers $\left(\pi_{J}\right)$ and the partial derivative of $\pi_{J}$ with respect to $n$ are

$$
\pi_{J} \equiv \pi_{D}+n \pi_{U i}=\frac{2 n+1}{4(1+n+m)^{2}}, \quad \frac{\partial \pi_{J}}{\partial n}=\frac{m-n}{2(1+n+m)^{3}} .
$$

$\pi_{J}$ is maximized $n=m$ if $2 m \leq N$, otherwise $n=N-m$. We have the following proposition.

Proposition 3 The optimal number of production units to be separated from the monopoly downstream firm is $m$ if $2 m \leq N$, otherwise $N-m$.

This proposition means that as the number of independent complementary input suppliers increases, the downstream firm tends to separate from its input production units. We now discuss the intuition behind this conclusion. As mentioned earlier, an increase in the number of input suppliers leads to an increase in the sum of the wholesale prices (the effect of double marginalization). An additional increase in the sum of wholesale prices, however, decreases as the number of input suppliers increases. ${ }^{12}$ Therefore, in our model, given that many independent input suppliers exist, a separation of an input unit does not diminish the quantity supplied by the downstream firm. In other words, the double marginalization

\footnotetext{
${ }^{12}$ This is somewhat similar to the standard Cournot quantity setting model. In this model, while an entry of a final product firm decreases the price, the additional contribution of the entry to the decrease in price becomes smaller as the number of existing firms increases.
} 
problem stemming from a separation is not severe. On the other hand, separation of an input unit decreases the sum of the wholesale prices set by the other input suppliers. This is somewhat similar to the "business stealing effect" in the standard Cournot model (Tirole (1988)). The reduction of the sum and the additional profit of the separated input unit benefit the group of the downstream firm and the separated unit. When the number of independent suppliers is large, the latter benefit dominates the former cost. When the number of separated units is greater than one, an additional separation of an input unit has a negative effect on the group of the downstream firm and the separated units. The additional separation reduces the profit(s) of the other separated unit(s) because of the business stealing by the additional unit. In other words, profit cannibalization among the separated units appears. This cannibalization diminishes the incentive to separate input units from the downstream firm. In this model, when the number of separated input units is equal to that of independent complementary input suppliers, the positive and the negative effects of vertical separation are balanced out. ${ }^{13}$

Remark 1 Note that, we have assumed that each upstream supplier has full bargaining power. When each upstream supplier has different bargaining power, the downstream firm separates at least one input unit if and only if

$$
2\left(1+\sum_{i=1}^{m} \frac{\alpha_{i}}{2-\alpha_{i}}\right) \sum_{i=1}^{m} \frac{\alpha_{i}}{2-\alpha_{i}}>\alpha_{j},
$$

where $\alpha_{i}$ is the bargaining power of independent supplier $i(i=1,2, \ldots, m)$ and $\alpha_{j}$ is the bargaining power of the separated input unit. The left-hand side of the inequality is increasing in each $\alpha_{i}(i=1,2, \ldots, m)$. As the number of independent suppliers and/or the bargaining power of each independent supplier increase, the downstream firm tends to separate from its input production unit.

\footnotetext{
${ }^{13}$ Novak and Stern (2009) empirically show a similar tendency that the probability of vertical integration for each automobile system increases in share of other systems that are vertically integrated.
} 
Remark 2 We have considered one-shot games concerning the decision of vertical separation. If we consider the following story, Proposition 3 slightly changes. Initially, the downstream firm, $m$ independent suppliers, and many potential buyers of the downstream firm's input production units exist. The downstream firm has an opportunity to sell its production units to buyers in each period. There is no time discount. In this case, the agents anticipate subsequent opportunities of vertical separation. As mentioned earlier, given the existence of independent input suppliers, the downstream firm has an incentive to sell its input units. As the number of outside suppliers increases, the incentive becomes stronger. Therefore, each agent can anticipate that the downstream firm has an incentive to sell its production units completely. This case is the worst for each upstream supplier because the profit of each supplier is decreasing in $n$ (see (12)). Potential buyers anticipate the profit of each suppliers as follows:

$$
\pi_{U}=\frac{1}{2(1+(N-m)+m)^{2}}=\frac{1}{2(1+N)^{2}} .
$$

This is also the willingness to pay of each buyer. The downstream firm's maximization problem is

$$
\max _{n} \frac{1}{4(1+n+m)^{2}}+n \times \frac{1}{2(1+N)^{2}} .
$$

The solution depends on the exogenous values $m$ and $N .{ }^{14}$ Fortunately, we can say that there are at most two candidates to be the optimal solution: $n=0$ and $n=N-m$. We can easily show that the downstream completely sells its input production units if and only if $N<m(3+2 m)$. The main massage of Proposition 3 does not so change. That is, as the number of independent complementary input suppliers increases, the downstream firm tends to separate from its input production units.

\footnotetext{
${ }^{14}$ The first-order condition is

$$
\frac{(m+1)^{3}-(N+1)^{2}+n\left(3(m+1)^{2}+3(m+1) n+n^{2}\right)}{2(N+1)^{2}(1+m+n)^{3}} .
$$
}

This is monotonically increasing in $n$. The second-order condition is positive. That is, the objective function is a convex function of $n$. 


\section{Discussion}

We have shown that when independent suppliers have greater bargaining power and/or when the number of independent suppliers is large, a downstream firm tends to separate from its input production units.

We believe that the difference between Japanese and US auto manufacturers is a suitable example of our results. Moreover, we suggest that our paper provides a new theoretical insight into those differences. From our results, we make the following prediction. When the number of high-quality input suppliers that tend to have stronger bargaining power is small, assemblers tend to produce other complementary components in-house, as US assemblers did. The converse also holds true. When the number of high-quality input suppliers is large, assemblers tend to separate from design and/or manufacture of other complementary components, as Japanese assemblers did.

Relying on the survey provided by Cusumano and Takeishi (1991) and the discussion in Richardson (1993) and Novak and Eppinger (2001), we now propose that Japanese suppliers truly have strong bargaining power and/or provide high-quality product to auto assemblers. More than two decades ago, Japanese auto manufacturers benefited from significant cost advantages over their US competitors. A visible difference between Japanese and US auto assemblers is their vertical structures concerning supplier relations. Japanese auto assemblers are known to be substantially less vertically integrated than their US counterparts. Large Japanese auto assemblers such as Toyota and Nissan rely on suppliers for both design and manufacture of components traditionally produced in-house by GM and Ford. Cusumano and Takeishi (1991) discuss several differences among the US and the Japanese automakers, including (1) number and type of suppliers; and (2) pricing practices. ${ }^{15}$ We

\footnotetext{
${ }^{15}$ For the other differences of supplier-manufacturer relationships among US and Japanese automakers, they list the following: role in product development, quality management, length and stability of relationships, and information exchanges and suggestions.
} 
first consider the number of suppliers and the types of suppliers. The Japanese automobile industry tends to be organized in a pyramid structure. Suppliers that directly negotiate with automobile assemblers also have their own suppliers. These sub-suppliers also have their own suppliers. As a result, hierarchies of suppliers (a pyramid of suppliers) are organized. In contrast, US automakers seem to buy more lower-level components and have several independent suppliers for each component. Hence, Japanese automakers negotiate with fewer suppliers than their US counterparts. In other words, Japanese automakers face a small number of (collected) bigger suppliers. Hence, Japanese automakers have weaker bargaining power than the US firms. We now consider pricing practices. US automakers choose their suppliers by utilizing competitive bidding, while the Japanese automakers utilize target pricing in which they help their suppliers to reach their targets. Hence, it is difficult for US suppliers to raise their prices. That is, US automakers have stronger bargaining power; conversely, Japanese automakers have weaker bargaining power. Summarizing the arguments, we conclude that there is a relationship between vertical integration and automakers' bargaining power. When suppliers have stronger bargaining power, assemblers and input production units tend to be vertically separated.

Moreover, Cusumano and Takeishi (1991) compare supplier type by financial affiliation and country of origin (see also Dyer (1996)). In their paper, the data indicate that 50\% of the major suppliers for the US automakers were internal parts divisions while $45 \%$ were independent US suppliers; 5\% (1 supplier) was from West Germany. ${ }^{16}$ For the Japanese automakers responding to the survey, a mere $7 \%$ of their suppliers were in-house divisions; $33 \%$ were affiliated firms (defined as minimum $20 \%$ equity ownership) and nearly $60 \%$ were independent. ${ }^{17}$ As mentioned in the introduction, Clark and Fujimoto (1991) and Clark

\footnotetext{
16 The sample size is relatively small. They do not provide statistical tests.

17 They conclude that these numbers appear consistent with previous reports of higher levels of vertical integration for US automakers in contrast to more outside suppliers for the Japanese. The responses from the transplants resembled the Japanese in the low level of vertical integration, but with far more reliance on US suppliers.
} 
(1989) found that Japanese suppliers have superior technologies that enable Japanese automakers to produce high-quality products (see also Hemmert (1999)). To avail themselves of the large number of independent suppliers that have superior technology, Japanese automakers may separate from their input production units, and these units may then be operated as affiliated suppliers. This organizational structure is quite different from that of US automakers.

\section{Concluding Remarks}

We provide a simple model to investigate decisions of vertical separation and show several new results that have not been explained in previous research. The key feature in this model is that there is more than one input required to produce the final product of the downstream monopolist. This feature is consistent with the organizational structures in the aircraft, automobile, and computer industries. We show that as the bargaining power of the independent supplier increases, the downstream monopolist tends to separate from its input unit. A corollary of this result is that when the bargaining power of the independent supplier is sufficiently large, vertical separation is always profitable for the downstream monopolist. We also show that as the number of independent complementary input suppliers increases, the downstream monopolist tends to separate from its input production units. The results are related to a visible difference between the vertical structures of Japanese and US auto assemblers.

From our results, we have a testable hypothesis for vertical structures: the larger the number of independent suppliers that have superior skills, the larger the number of separated input units from assemblers. A rigorous empirical test is needed to show whether the prediction is plausible or not. This is a consideration for future research. 


\section{References}

Ahmadjian, C. L. and Lincoln, J. R., 2001, 'Keiretsu, Governance, and Learning: Case Studies in Change from the Japanese Automotive Industry', Organization Science 12, pp. $683-701$.

Arya, A., Mittendorf, B., and Sappington, D.E.M., 2008, 'The Make-or-Buy Decision in the Presence of a Rival: Strategic Outsourcing to a Common Supplier', Management Science 54, pp. 1747-1758.

Baldwin, C.Y., and Woodard, C.J., 2007, 'Competition in Modular Clusters', Working Paper, Harvard Business School.

Beelaerts van Blokland, W.W.A., Verhagen, W.J.C., and Santema, S.C., 2008, 'The Effects of Co-Innovation on the Value-Time Curve: A Quantitative Study on Product Level', Journal of Business Market Management 2, pp. 5-24.

Bonanno, G. and Vickers, J., 1988, 'Vertical Separation', Journal of Industrial Economics 36 , pp. $257-265$.

Casadesus-Masanell, R., Nalebuff, B., and Yoffie, D., 2007, 'Competing Complements', Working Paper, Harvard Business School.

Che, Y.-K. and Sákovics, J., 2008, 'Hold-up Problem', in Durlauf, S.N. and Blume, L.E. (eds.), The New Palgrave Dictionary of Economics, Second Edition, (Macmillan, London).

Chen, Y., 2001, 'On Vertical Mergers and Their Competitive Effects', RAND Journal of Economics 32, pp. 667-685.

Chen, Y., 2005, 'Vertical Disintegration', Journal of Economics and Management Strategy 14, pp. 209-229.

Choi, J. P. and Yi, S.-S., 2000, 'Vertical Foreclosure with the Choice of Input Specifications', Rand Journal of Economics, 31, pp. 717-743.

Clark, K.B., 1989, 'Project Scope and Project Performance: The Effect of Parts Strategy and Supplier Involvement in Product Development', Management Science 35, pp. 12471263.

Clark, K.B. and Fujimoto, T., 1991, Product Development Performance, Strategy, Organization, and Management in the World Auto Industry, (Harvard Business School Press, Boston).

Coase, R. 1937, 'The Nature of the Firm', Economica 4, pp. 386-405. 
Cournot, A. 1838, 'Researches into the Mathematical Principles of the Theory of Wealth', (Macmillan, New York); English translation, N. Bacon, 1897.

Cusumano, M. and Takeishi, A., 1991, 'Supplier Relations and Management: A Survey of Japanese, Japanese-transplant, and U.S. Auto Plants', Strategic Management Journal 12 , pp. $563-588$.

Davidson, C., 1988, 'Multiunit Bargaining in Oligopolistic Industries', Journal of Labor Economics 6, pp. 397-422.

Dore, R. 1983, 'Goodwill and the Spirit of Market Capitalism' British Journal of Sociology 34, pp. 459-482.

Dowrick, S., 1989, 'Union-Oligopoly Bargaining', Economic Journal 99, pp. 1123-1142.

Dyer, J., 1996, 'Does Governance Matter? Keiretsu Alliances and Asset Specificity as Sources of Japanese Competitive Advantage', Organization Science 7, pp. 649-666.

Dyer, J.H. and Nobeoka, K., 2000, 'Creating and Managing a Highperformance KnowledgeSharing Network: The Toyota Case', Strategic Management Journal 21, pp. 345-367.

Economides, N. and Salop, S.C., 1992, 'Competition and Integration Among Complements, and Network Market Structure', Journal of Industrial Economics 40, pp. 105-123.

Emerson, R. M., 1962, 'Power-Dependence Relations', American Sociological Review 27, pp. $31-40$.

Gal-Or, E., 1999, 'Vertical Integration or Separation of the Sales Function as Implied by Competitive Forces', International Journal of Industrial Organization 17, pp. 641-662.

Gaudet, G. and Long, N.V., 1996, 'Vertical Integration, Foreclosure, and Profits in the Presence of Double Marginalization', Journal of Economics and Management Strategy 5, pp. 409-432.

Grossman, S. and Hart, O., 1986, 'The Costs and Benefits of Ownership: A Theory of Lateral and Vertical Integration', Journal of Political Economy 94, pp. 691-719.

Grout, P. 1984, 'Investment and Wages in the Absence of Binding Contracts: A Nash Bargaining Approach', Econometrica 52, pp. 449-460.

Hart, O. and Moore, J., 1990, 'Property Rights and the Nature of the Firm', Journal of Political Economy 98, pp. 1119-1158.

Hart, O. and Tirole, J., 1990, 'Vertical Integration and Market Foreclosure', Brookings Papers on Economic Activity: Microeconomics, pp. 205-276.

Hemmert, M., 1999, “Intermediate Organization' Revisited: a Framework for the Vertical Division of Labor in Manufacturing and the Case of the Japanese Assembly Industries', Industrial and Corporate Change 8, pp. 487-517. 
Hill, C. W. L., 1995, 'National Institutional Structures, Transaction Cost Economizing, and Competitive Advantage: The Case of Japan', Organization Science 6, pp. 119-131.

Horn, H. and Wolinsky, A., 1988a, 'Bilateral Monopolies and Incentives for Merger', RAND Journal of Economics 19, pp. 408-419.

Horn, H. and Wolinsky, A., 1988b, 'Worker Substitutability and Patterns of Unionization', Economic Journal 98, pp. 484-497.

Kim, S.-H., 2004, 'Vertical Structure and Patent Pools', Review of Industrial Organization 25, pp. 231-250.

Klein, B., Crawford, R. and Alchian, A., 1978, 'Vertical Integration, Appropriable Rents, and the Competitive Contracting Process', Journal of Law and Economics 21, pp. 297 326.

Laussel, D., 2008, 'Buying Back Subcontractors: The Strategic Limits of Backward Integration', Journal of Economics and Management Strategy 17, pp. 895-911.

Lerner, J. and Tirole, J., 2004, 'Efficient Patent Pools', American Economic Review 94, pp. $691-711$.

Lin, P., 2006, 'Strategic Spin-Offs of Input Divisions', European Economic Review 50, pp. 977-993.

Lommerud, K.E., Meland, F., and Sørgard, L., 2003, 'Unionised Oligopoly, Trade Liberalisation and Location Choice', Economic Journal 113, 782-800.

Lommerud, K.E., Meland, F., and Straume, O.R., 2009, 'Can deunionization lead to international outsourcing?', Journal of International Economics 77, 109-119.

Ma, C.-T. A., 1997, 'Option Contracts and Vertical Foreclosure', Journal of Economics and Management Strategy 6, pp. 725-753.

Maruyama, M. and Minamikawa, K., 2009, Vertical Integration, Bundled Discounts and Welfare, Information Economics and Policy 21, pp. 62-71.

Matsushima, N., forthcoming, 'Vertical Merger and Product Differentiation', Journal of Industrial Economics.

McAfee, R.P. and Schwartz, M., 1994, 'Opportunism in Multilateral Vertical Contracting: Nondiscrimination, Exclusivity, and Uniformity', American Economic Review 84, pp. 210-30.

Mumford, K. and Dowrick, S., 1994, 'Wage Bargaining with Endogenous Profits, Overtime Working and Heterogeneous Labor', Review of Economics and Statistics 76, pp. 329336. 
Nalebuff, B.J., 2000, 'Competing Against Bundles', in Peter J. Hammond and Gareth D. Myles, eds., Incentives, Organization, and Public Economics: Papers in Honour of Sir James Mirrlees pp. 323-336, (Oxford University Press, Oxford, UK).

Naylor, R.A., 2002, 'Industry Profits and Competition under Bilateral Oligopoly', Economics Letters 77, pp. 169-175.

Nishiguchi, T., 1994, Strategic Industrial Sourcing, New York: Oxford University Press.

Novak, S. and Eppinger, S.D., 2001, 'Sourcing by Design: Product Complexity and the Supply Chain', Management Science 47, pp. 189-204.

Novak, S. and Stern, S., 2009. 'Complementarity Among Vertical Integration Decisions: Evidence from Automobile Product Development', Management Science 55, pp. 311332 .

O'Brien, D.P. and Shaffer, G., 1992, 'Vertical Control with Bilateral Contracts' RAND Journal of Economics 23, pp. 299-308.

Ordover, J., Saloner, G., and Salop, S., 1990, 'Equilibrium Vertical Foreclosure', American Economic Review, 80, pp. 127-142.

Pepall, L. and Norman, G., 2001, 'Product Differentiation and Upstream-Downstream Relations', Journal of Economics and Management Strategy, 10, pp. 201-233.

Perry, M. K., 1989, 'Vertical Integration', in R. Schmalensee and R. Willing (Eds.), Handbook of Industrial Organization, Amsterdam, The Netherlands: North-Holland, pp. 1985-2055.

Pfeffer, J. and Salancik, G., 1978, The External Control of Organizations, New York: Harper \& Row.

Rey, P. and Tirole, J., 2007, 'A Primer on Foreclosure', in Armstrong, M. and Porter, R.H. (eds.), Handbook of Industrial Organization, Vol. 3 (Elsevier, Amsterdam, The Netherlands).

Richardson, J., 1993, 'Parallel Sourcing and Supplier Performance in the Japanese Automobile Industry', Strategic Management Journal 14, pp. 339-350.

Riordan, M.H. 1998, 'Anticompetitive Vertical Integration by a Dominant Firm', American Economic Review 88, pp. 1232-1248.

Sako, M., 1991, 'The Role of 'Trust' in Japanese Buyer-Supplier Relationships', Richerche Economiche 45, pp. 449-474.

Sonnenschein, H., 1968, 'The Dual of Duopoly Is Complementary Monopoly: or, Two of Cournot's Theories Are One', Journal of Political Economy 76, pp. 316-318. 
Scherer, F. M., 1980, Industrial Market Structure and Economic Performance, 2nd Edition, Chicago, IL: Rand-McNally.

Schmidt, K.M., 2008, 'Complementary Patents and Market Structure', CEPR Discussion Papers 7005.

Sheard, P., 1994, 'Interlocking Shareholdings and Corporate Governance in Japan', in M. Aoki and R. Dore (Eds.), The Japanese Firm: Sources of Competitive Strength, New York: Oxford University Press.

Thesmar, D. and Thoenig, M., 2007, 'From Flexibility to Insecurity: How Vertical Separation Amplifies Firm-level Uncertainty', Journal of the European Economic Association 5, pp. 1161-1202.

Williamson, O. 1979, 'Transaction-Cost Economics: the Governance of Contractual Relations', Journal of Law and Economics 22, pp. 233-262. 

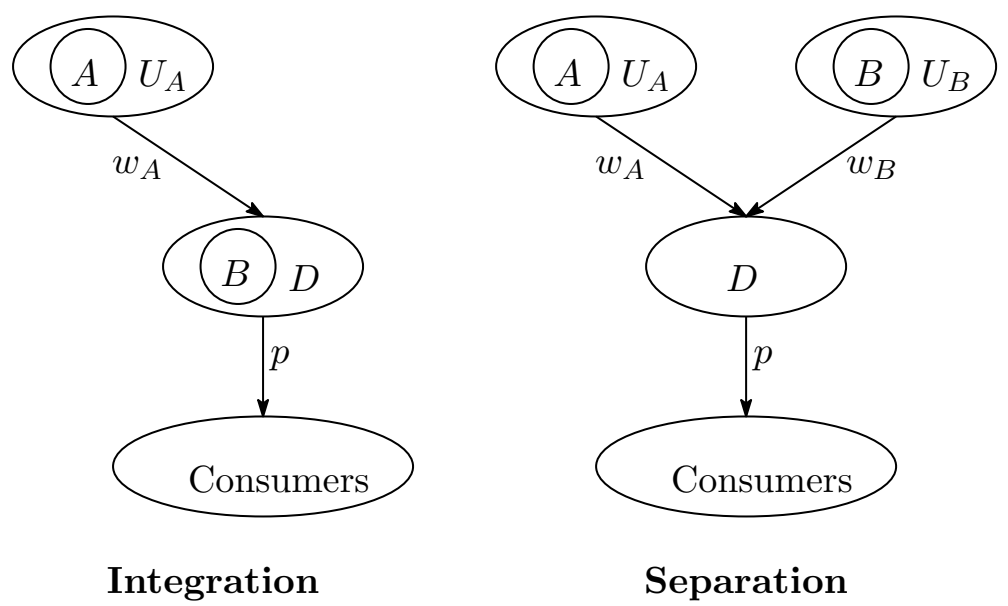

Figure 1: The market structure 


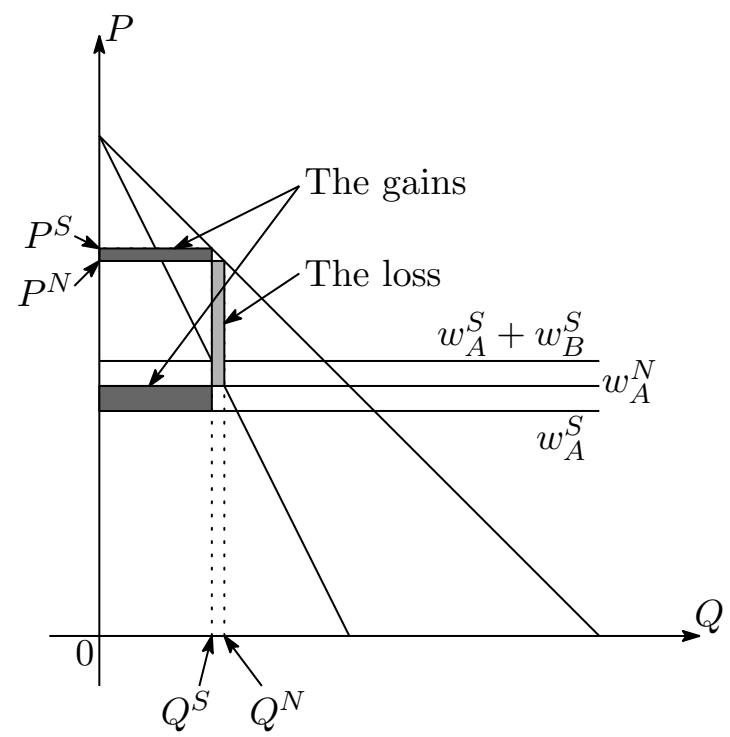

Figure 2: The change caused by vertical separation 


\section{Technical Appendix}

We now consider the case in which the technology function of the downstream firm has a Cobb-Douglas form, $Y=q_{A}^{1 / 2} q_{B}^{1 / 2}$. Given the wholesale prices $w_{A}$ and $w_{B}$, when the downstream firm produces the amount of $Q$, it solves the following minimization problem:

$$
\min _{q_{A}, q_{B}} w_{A} q_{A}+w_{B} q_{B} \quad \text { s.t. } Q=q_{A}^{1 / 2} q_{B}^{1 / 2} .
$$

From the problem, we have the following equation:

$$
q_{A}=\left(\frac{w_{B}}{w_{A}}\right)^{1 / 2} Q, \quad q_{B}=\left(\frac{w_{A}}{w_{B}}\right)^{1 / 2} Q
$$

When the downstream monopolist produces the amount of $Q$, the production cost is

$$
C(Q) \equiv 2 w_{A}^{1 / 2} w_{B}^{1 / 2} Q
$$

From the maximization problem of the monopolist, the optimal quantity supplied is

$$
Q^{*}=\frac{1-2 w_{A}^{1 / 2} w_{B}^{1 / 2}}{2}
$$

The objective functions of the upstream units are described as follows:

$$
\pi_{A}=\frac{\left(w_{A}-c\right)\left(1-2 w_{A}^{1 / 2} w_{B}^{1 / 2}\right)}{2}, \quad \pi_{B}=\frac{\left(w_{B}-c\right)\left(1-2 w_{A}^{1 / 2} w_{B}^{1 / 2}\right)}{2} .
$$

The optimization problems lead to

$$
w_{A}=w_{B}=\frac{1+c}{3}, \quad \pi_{D}^{S}+\pi_{B}^{S}=\frac{(1-2 c)^{2}}{12} .
$$

When the downstream firm integrates upstream unit $B, w_{B}=c$. From first-order condition yields

$$
w_{A}=\frac{1+6 c^{2}+\sqrt{1+12 c^{2}}}{18 c}, \quad \pi_{D}^{N}=\frac{1}{36}\left(-3+\sqrt{2\left[1+6 c^{2}+\left(1+12 c^{2}\right)^{1 / 2}\right]}\right)^{2} .
$$

By plotting $\pi_{D}^{S}+\pi_{B}^{S}-\pi_{D}^{N}$, we have the following figure. Numerically solving $\pi_{D}^{S}+\pi_{B}^{S}-$ $\pi_{D}^{N}=0$ for c, we obtain $c=0.5$. Because $\pi_{D}^{S}+\pi_{B}^{S} \geq \pi_{D}^{N}$, vertical separation is profitable for the integrated downstream firm (see Figure A1). 


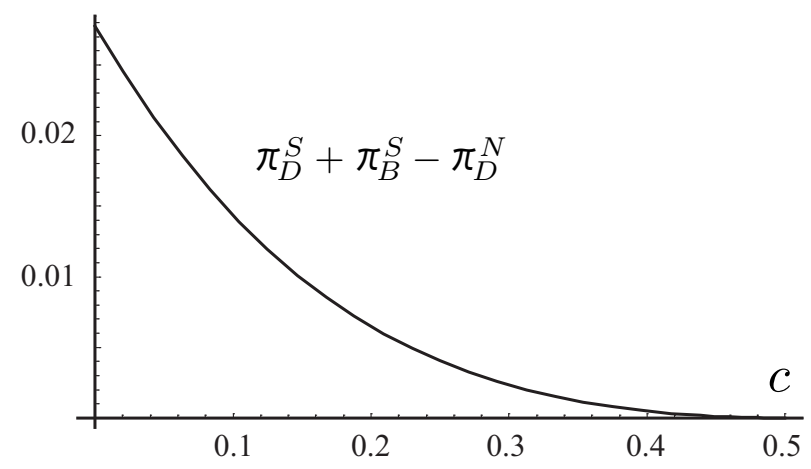

Figure A1: $\pi_{D}^{S}+\pi_{B}^{S} \geq \pi_{D}^{N}$ 